\title{
La guerra internacional por el equipo sanitario
}

\author{
International war for medical equipment
}

\begin{abstract}
${ }^{1}$ Edith Diana Ramírez Charca Universidad Nacional Jorge Basadre Grohmann. Departamento Académico de Ingeniería Comercial, Perú ORCID: 0000-0001-6750-4957

E-mail:diana.ingeco@gmail.com

${ }^{2}$ William B. Campos Lizarzaburu Estudios para el Desarrollo, Perú ORCID: 0000-0002-9654-5915

RESUMEN

E-mail: wbclizarzaburu@gmail.com

Esta investigación tuvo como objetivo describir los acontecimientos de la guerra internacional por el equipo sanitario en tiempos de la pandemia del COVID-19, sucedida en marzo del presente año. Se identificaron el país agresor, el país agredido y el material objeto de la acción de intervención, y así se elaboró un estudio documental de enfoque cualitativo y con orientación interpretativa, también se trabajó sobre la base de información que procedió de fuentes documentales de habla hispana (periódicos digitales disponibles en la red). La información se organizó en una tabla donde se presenta información sobre el periodo, acontecimiento, países involucrados y modo en que se resolvió el conflicto. Se encontró que varios países participaron en el conflicto (Francia, Estados Unidos, España, Alemania, Turquía y otros), tanto como agresores y como víctimas, operando con reglas de mercado que desestimaron las reglas del comercio internacional actual.
\end{abstract}

Palabras clave: Conflicto, equipo de protección sanitario, guerra de las mascarillas, mascarilla, ventilador mecánico.

\begin{abstract}
This study was intended to describe the events of the international war for medical equipment during the COVID-19 pandemic, which occurred in March of this year. The aggressor country, the country attacked and the required material of the intervention action were identified to elaborate qualitative documentary research with an interpretive approach using databases proceed from Hispanic documental sources (digital newspaper). The information was organized in a table data setting the period, the events, the involved countries and the resolution of the conflict. Several countries participated in the conflict (France, U.S., Spain, Germany, Turkey and others) aggressors countries, as well as victims, were operating with market rule that dismisses the current international commerce terms.
\end{abstract}

Keywords: Conflict, medical equipment, the war of masks, mask, mechanical ventilation.

\section{INTRODUCCIÓN}

\section{El contexto del comercio internacional}

Desde los últimos años del siglo pasado, se reconoce que el mundo experimenta cambios acelerados en diferentes dimensiones de su actividad, sobre todo en las dimensiones económica y tecnológica. Precisamente, porque la celeridad de los movimientos, que se verifican en esas esferas de actividad, ha puesto en evidencia la ineficacia de medidas tradicionales de control y regulación de transacciones comerciales e inversiones 
internacionales, se realizan esfuerzos para dar forma a un entorno económico donde se flexibilizan las fronteras y se reducen al máximo las regulaciones al comercio internacional (Gazol, 2016). En ese contexto, la Organización Mundial del Comercio (OMC en adelante) ha privilegiado un conjunto de seis principios, que proporcionan el marco para un creciente y más eficiente comercio internacional. Esos principios son: la no discriminación, que implica un acercamiento indiferenciado a sus interlocutores comerciales; una mayor apertura, que implica la reducción de obstáculos al comercio; previsibilidad y transparencia, que implica la confianza de los inversores y gobiernos de otros países que no se obstaculizará el comercio; mayor competitividad, que implica frenar prácticas desleales; promover ventajas para los países en desarrollo; y la protección del medio ambiente (OMC, 2019). Cabe señalar que los Acuerdos de la OMC consideran mercancías, servicios e incluso propiedad intelectual (OMC, 2019).

En ese marco auspicioso, diferentes países del mundo, China e India, en Asia; Brasil, en Sudamérica, encontraron una vía para potenciar su crecimiento económico (Giordano, 2019) por encima de los valores promedio de países con economías tradicionalmente mucho más sólidas, como la de Estados Unidos o las del viejo continente. India y China alcanzaron promedios cercanos al 7 \% (Barrera, 2019), superando incluso a las economías de los tigres asiáticos, que destacaron en las décadas finales del siglo anterior, mientras que Estados Unidos, en una racha de expansión que venía desde el 2009, apenas creció un promedio anual de 2.3 \% (Pozzi, 2019).

Sin embargo, a pesar del estímulo de la OMC y de la fuerte tendencia globalizante que se verificaba desde la última década del siglo XX (Cox, 2008), en los últimos años de la década presente se empezó a experimentar una desaceleración del comercio mundial, que iba de la mano con un pequeño pero creciente incremento de barreras comerciales en algunos países (Comisión Económica para América Latina y el Caribe, 2019) y con posturas políticas que alentaban muy poco la integración. Entre ellos, los Estados Unidos con su presidente Donald Trump a la cabeza, y el Reino Unido, con el Brexit, ponían freno a la velocidad de la globalización recurriendo a medidas proteccionistas (Viani, 2019) y al debilitamiento de la más importante experiencia integracionista, la Unión Europea (Rosales, 2018).

Si bien el Reino Unido optó por la separación de la Unión Europea en un proceso que derivó en incertidumbre política, económica (Malfeito, 2017) y social (Idígoras, 2017), la administración de Trump en los Estados Unidos, fue mucho más lejos en su desprecio de las relaciones comerciales internacionales, en tanto, impulsó la salida del Acuerdo de París, la salida del Acuerdo de Asociación Transpacífico (TPP por sus siglas en inglés) y estimuló el boicot de la nominación de árbitros de la OMC (Rosales, 2018), además, impuso una serie de restricciones a la importación de bienes y a las inversiones procedentes de China (Meltzer y Shenai, 2019). Tan solo el 2018, las medidas dictadas unilateralmente por Estados Unidos contra China, incluían aranceles del 30\% y $50 \%$ a la importación de paneles solares y lavadoras, del $25 \%$ y $10 \%$ a la importación de acero y aluminio, y del $25 \%$ sobre bienes tecnológicos, entre otras medidas (Viani, 2019).

Como una justificación de su proceder, y en acuerdo con su discurso de campaña, Trump terminó culpando al comercio internacional (sobre todo, al comercio bilateral con China) de situaciones sociales que venía atravesando el poblador estadounidense, entre las cuales destacan el deterioro de la calidad de vida, debido al estancamiento de las remuneraciones, y la pérdida de empleos fabriles, debido a que muchas empresas habían trasladado sus centros de operaciones a países con mano de obra barata desde décadas atrás, lo que suponía para el poblador acceder a un mercado laboral de baja remuneración.

Como un corolario esperado, se generaron tensiones entre Estados Unidos y China (Viani, 2019), que se agravaron cuando la administración Trump terminó apuntando sus baterías contra una de las empresas líderes en tecnología celular, Huawei (Agosin, 2018). Lo cierto es que en la actualidad, en una economía global altamente integrada, es difícil para los gobiernos restringir la integración tecnológica, en base a la noción de nacionalidad (Schneider-Petsinger, Wang, Jie y Cabtree, 2019). Por otro lado, la capacidad tecnológica de China, junto con su sistema político distintivo en el país, está remodelando el orden tecnológico y económico mundial (SchneiderPetsinger et al., 2019) sobre la base del propósito de China, que no se reduce solo a adoptar tecnología de punta, sino también a establecer estándares tecnológicos internacionales.

En consecuencia, el poder económico de China se ha incrementado a lo largo de las décadas recientes, con un promedio que para 2018, el año de menor crecimiento en 28 años, alcanzó 6.6 \% (Barrera, 2019), en tanto que la 
presencia de Estados Unidos, en el comercio internacional y la producción global, ha ido declinando (Kapustina, Lipková, Silin y Drevalev, 2020). En ese sentido, la visión de dominio absoluto de Estados Unidos en la economía global, ha entrado en conflicto con el creciente desbalance en el comercio bilateral con China, incrementando la competitividad de las empresas de alta tecnología y la exportación de inversiones.

Por otra parte, Estados Unidos y la Unión Europea, han sostenido relaciones comerciales muy cercanas. Hasta 2017 sus relaciones comerciales estuvieron dominadas por la Transatlantic Tradeand Investment Partnership (TTIP), en la que se consiguieron algunos logros modestos durante las rondas de negociación. En ese sentido, si bien no siempre la Unión Europea y los Estados Unidos han tenido una visión común en torno de determinadas cuestiones de política exterior, lo cierto es que se han mantenido como los más importantes aliados entre sí (Damen y Turunen, 2018).

En contraste con el gobierno de Obama, la administración de Trump adoptó un enfoque diferente en sus relaciones con la Unión Europea. Puso en primer término los intereses nacionales, y se propuso reordenar los déficits en cuanto a balanza comercial con otros países. Una de esas medidas incluyó la finalización de las exenciones temporales concedidas a la Unión Europea (Viani, 2019), dejando sin efecto el TTIP. Se despertaron tensiones que solo cedieron cuando se declaró una tregua en julio del 2018, en la que se acordó reiniciar las negociaciones comerciales bilaterales, aunque se hizo evidente que no se tenía todavía una agenda común y el hecho de que cada parte tenía metas muy diferentes en perspectiva (Hamilton, 2019).

Sin embargo, después del momento de fricción que se suscitó, lo cierto es que la Unión Europea da forma en conjunto, al mercado de exportación más extenso que Estados Unidos puede tener para sus productos industriales; y a su vez, Estados Unidos representa el mayor mercado de exportación para la Unión Europea (Viani, 2019). Así, incluso a pesar del giro en la política comercial de Trump, las economías conjuntas de la Unión Europea y Estados Unidos, representaban casi $50 \%$ del producto interno bruto mundial y un tercio del comercio mundial (Damen y Turunen, 2018). Y esa tendencia, no hizo más que acentuarse con el correr de los meses, pues durante el 2019 la Unión Europea exportó a Estados Unidos más de 400 mil millones de euros, con importaciones de 267 mil millones, lo cual significaba una balanza comercial positiva de 139 mil millones (Damen, 2019).

En síntesis, el panorama del comercio internacional muestra un conjunto de características relevantes, entre las que destacan las siguientes: Primero, la OMC defendiendo los principios que preconizan el libre comercio internacional. Segundo, un Estados Unidos que ha optado por poner en marcha medidas proteccionistas, en su afán por contener la expansión de China. Tercero, una China que toma protagonismo tanto en la economía como en la tecnología a escala mundial. Y finalmente, una Unión Europea que sigue en cierto modo lo que Estados Unidos dicta, pero desde una perspectiva más bien secundaria, antes que protagónica. Estas son las características con las que prácticamente se desarrolla y finaliza el año 2019 y se configura el escenario que da principio al año 2020.

\section{Una guerra inusual}

El año 2020 se inicia con una escalada de agresión internacional, protagonizada por la administración Trump, al atacar un blanco iraní (Marcus, 2020), cuyo análisis no se corresponde con los fines de este estudio, al mismo tiempo que sonaban lejanas las noticias de una epidemia por una nueva cepa de coronavirus en la ciudad de Wuhan, en China (Organización Mundial de la Salud, 2020), a la que se denominó COVID-19. Lo cierto es que, en el marco de una cultura digital en permanente movilidad, las noticias de la epidemia arribaron a Europa y América, sin provocar mayor reacción que un sinnúmero de bromas ante lo que ocurría en China y las posibles razones de la transmisión de la nueva cepa del virus a los humanos. Así transcurrió enero y parte de febrero, mientras varios de los líderes mundiales de occidente, minimizaban la expansión de la epidemia de oriente, como si se tratara de una simple gripe, y no prestaban mayor atención a los posibles focos de contagio en sus respectivos países.

En consecuencia, entre mediados de febrero y principios de marzo, el nuevo coronavirus atravesó las fronteras de países europeos y obligó a los gobiernos a plantearse la cuestión de si era necesario tomar medidas importantes para frenar el avance de la epidemia, o sencillamente dejarla pasar como lo que se pensaba que era, una suerte de gripe estacional o algo parecido a ello. Al final, se consideró que algunas medidas sanitarias a tomar en cuenta, 
serían suficientes para paliar los posibles impactos de la epidemia, entre las cuales empezaron a vislumbrarse dos acciones: El uso de mascarillas de protección sanitaria, como primera medida de contención del nuevo virus, y la adquisición de ventiladores mecánicos para quienes en posibles casos de enfermedad grave, requerían de cuidados intensivos.

Cuando se empezó a considerar la posible importancia de las mascarillas sanitarias y el hecho de que el $90 \%$ de ellas se fabrican en China (Kryazhev, 2020), en medio de discusiones en el sentido de si estas eran necesarias o no, o si eran útiles para evitar el contagio o no, algunos gobiernos empezaron una escalada de acciones por adquirirlas, que desafiaban la razonabilidad y cordialidad de los principios que la OMC se había encargado de formular y pulir a lo largo de los años. Se dio inicio a un conflicto entre responsables sanitarios de diferentes gobiernos, que se transformó en una carrera sin escrúpulos (Cantón, 2020) por adquirir las mascarillas, la que ha terminado calificándose como la guerra de las mascarillas (Ayuso, 2020; Cantón, 2020; Hidalgo, 2020; Kryazhev, 2020; Mergier, 2020).

Esta guerra se inició a principios de marzo, cuando el gobierno francés retuvo un avión con material médico con destino a España (entre el cual iban 4 millones e mascarillas), por dos semanas, y devolvió solo parte del cargamento de mascarillas destinadas a su vecino (Arias-Borque, 2020); y empezó a endurecerse cuando algunos países productores, sobre todo India, Turquía y Estados Unidos, prohibieron su exportación con el propósito de abastecer a sus propios hospitales (Gozzer, 2020). La acción de Francia motivó incluso la intervención del gobierno sueco, ante quien reclamó la empresa proveedora, considerando todavía el marco del comercio internacional vigente.

La demanda de este sencillo protector se disparó cuando se hizo evidente que la nueva cepa de coronavirus seguía avanzando sobre todo en Europa, y su expansión se declaró como pandemia el 11 de marzo, por la Organización Mundial de la Salud. Se generó con ello un problema generalizado de abastecimiento en por lo menos el $85 \%$ de hospitales en el mundo (Gozzer, 2020).

Pero a medida que transcurrían los días, el modus operandi de los gobiernos o sus representantes, se iba haciendo más duro y exacerbado, y se agravó cuando la guerra no solo se enfocaba en mascarillas, sino también en prendas de protección médica, aparatos respiratorios, medicamentos, monitores de signos vitales e incluso camas. Por un lado, los países entran en una situación de urgencia que los lleva a considerar que todas las acciones son permitidas (Cantón, 2020); se vuelve un conflicto global donde todos los métodos parecen válidos (Kryazhev, 2020), de modo que sobre la marcha se modifican las reglas de juego, y se imponen reglas de economía de mercado, tales como la venta al mejor postor, y venta preferencial al cliente con mayor volumen de compra (Gozzer, 2020). Por otro lado, emergen individuos que quieren ganar dinero, para responder a la demanda de países que procuran las mascarillas por cualquier medio. Entonces, se genera una situación que algunos observadores califican como actos de piratería moderna (Euronews, 2020), aun cuando algunos gobiernos instan a que se cumplan las normas internacionales (Hidalgo, 2020).

La entrada en escena de los Estados Unidos, deriva en una serie de consecuencias no muy bien recibidas. Dadas las circunstancias, la demanda estadounidense es la más agresiva y posiblemente la más grande (Gozzer, 2020). Además, Estados Unidos compra a precios exorbitantes, que alcanzan tres o cuatro veces el valor previo de los productos encargados (Mergier, 2020).

Apenas un par de semanas después, el foco de la guerra se desplazó desde las mascarillas y el equipo de protección hacia los ventiladores mecánicos, y se inicia una nueva etapa de conflicto, que algunos hombres de prensa llamaron la guerra de los respiradores (Iglesias, 2020). ¿La razón? Además de las necesidades crecientes de diferentes países, tanto de Europa como de América, en cuanto a equipamiento para cuidados intensivos, se sostenía que en los siguientes meses, Estados Unidos podría llegar a necesitar unos 100 mil ventiladores (Gozzer, 2020). Ante esa posible demanda, los países productores (Italia, Irlanda) incrementaron su producción, pero no se daban abasto ni siquiera para cubrir sus propias necesidades, como ocurría en Italia.

Entonces, además de las medidas de incautación claramente arbitrarias y unilaterales que empezaban a practicarse más allá de Europa (EFE, 2020), se dio inicio a una nueva forma de negociación, frente a la forma común de efectuar las compras, con un $30 \%$ de adelanto en el momento del pedido, y un saldo a pagar de $70 \%$ cuando se recoge la mercancía; emergieron operadores de Estados Unidos que empezaron a pagar al contado (los 
maletines a pie de avión) (Arias-Borque, 2020), e incluso sin ver el material adquirido (Cantón, 2020).

Las consecuencias eran de esperarse, surgieron dificultades hasta para conseguir vuelos desde China (Kryazhev, 2020); se triplicó la tarifa de flete y se hizo muy difícil encontrar asientos, incluso en vuelos de carga; y se generó un clima de desconfianza entre gobiernos (Gozzer, 2020), lo que obligó a que estos consideraran como recibido un cargamento, solo cuando se encontrara en suelo propio (Cantón, 2020).

El acceso privilegiado a los respiradores, puso en evidencia que las ventas se estaban concretando aprovechando fisuras en el sistema de distribución (Arias-Borque, 2020). Esto significaba reconocer, por un lado, que la lógica de imposición del más fuerte, no era otra cosa que el paso por encima de las reglas internacionales del comercio y del derecho, de los principios éticos elementales, de la solidaridad e incluso del comportamiento apropiado entre las naciones (Mergier, 2020), por parte de los países ricos. Además, implicaba que las negociaciones se estaban haciendo sobre la base de la activación de mecanismos de corrupción, malversaciones y sobrefacturación en torno de la adquisiciones en los gobiernos que participaban del conflicto (Mergier, 2020).

Pero se empezaron a vislumbrar también otro tipo de corolarios, cuyos impactos aún permanecen en el debate, tales como el golpe subyacente al mercado común europeo (Mergier, 2020); el inevitable cuestionamiento respecto del comportamiento asumido por los diferentes países que participaron del conflicto, aun cuando las reglas de juego del comercio internacional seguían en vigor y los propósitos de cooperación internacional no se han desestimado; la salida a la luz del peor rostro político de los gobiernos; y el cuestionamiento a la lógica de la economía de mercado, cuando las necesidades requerían otro tipo de compromisos. Esta última llegó a darse incluso entre los estados de una misma nación, como sucedió en Estados Unidos (Mergier, 2020) y Brasil (Jeantet, 2020), lo cual linda en las proximidades del absurdo.

\section{Objetivo de investigación}

El escenario descrito pone en evidencia la necesidad de una constante reflexión, en torno a los propósitos y principios reclamados por el marco del comercio internacional, puesto que al parecer, no fueron lo suficientemente eficaces como se hubiera esperado para guiar la interacción entre los diferentes países, sobre todo en momentos en los que todavía los requerimientos exigidos por la pandemia permanecen. Considerando ese marco, la presente investigación se planteó como objetivo, describir algunos hechos relevantes de la llamada guerra internacional por el equipo sanitario en tiempos de la pandemia del COVID-19. Con esa intención, se procura identificar tres elementos clave: los actores involucrados, es decir, los gobiernos que participaron del conflicto; la dirección de la agresión y modo en que se hizo efectiva; y el producto o bien que fue objeto de conflicto.

\section{MATERIAL Y MÉTODOS}

Estudio documental (Gómez, 2011) de enfoque cualitativo (Bhattacherjee, 2012), orientado en el marco de la investigación interpretativa (Bhattacherjee, 2012).

Se trabajó con periódicos digitales de habla hispana publicados entre marzo y abril del presente año, disponibles en la red. Se utilizó como categoría de búsqueda la locución guerra de las mascarillas, que solo en Google genera cerca de 37 millones de resultados.

La información recogida se organizó en una tabla que presenta como encabezados los siguientes aspectos: fecha, acontecimiento, lugar donde ocurrieron los hechos, país agresor (sea por incautación de los bienes o por adquisición), país productor, país perjudicado, y forma como se resolvió el hecho. 


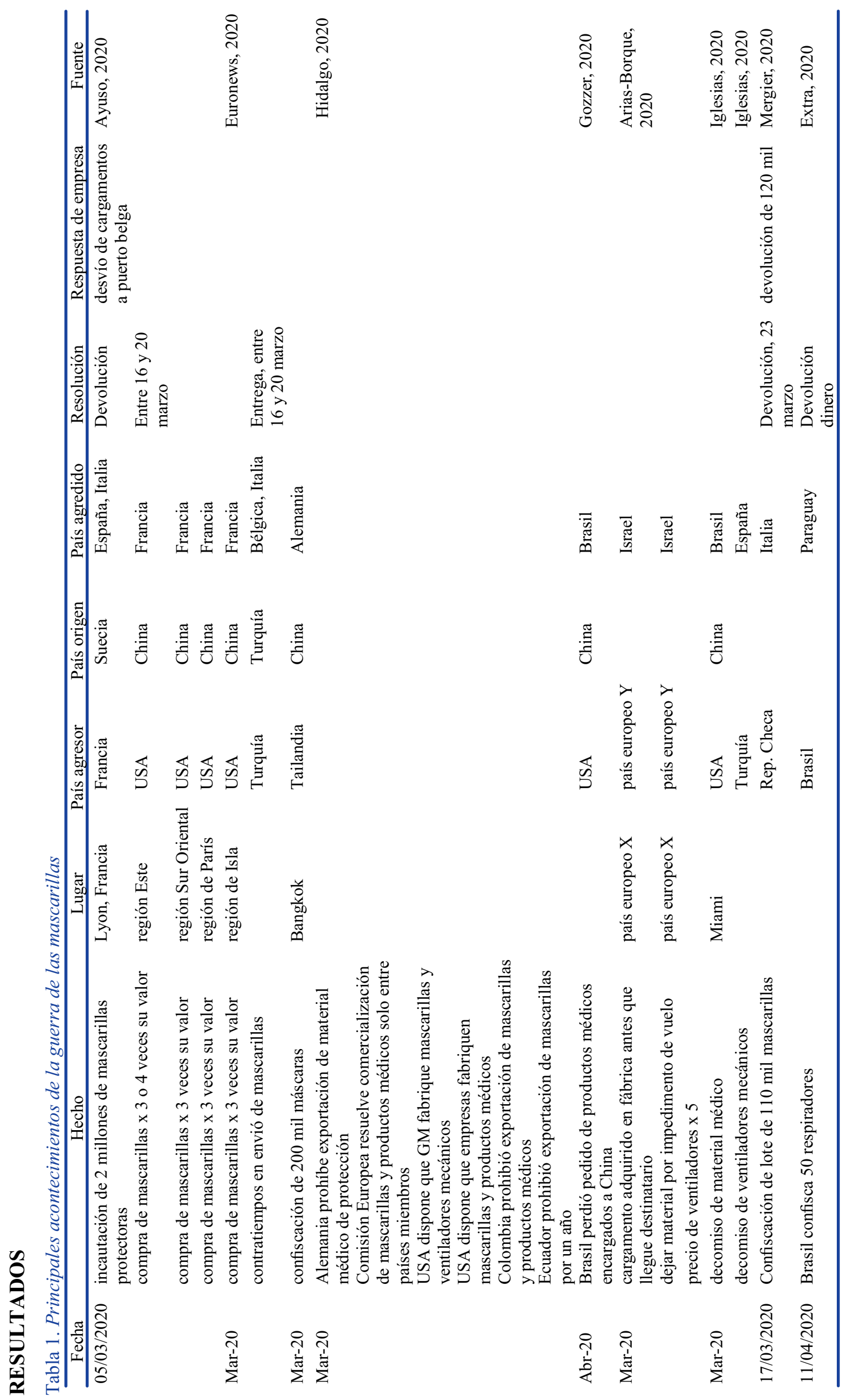


Se identificaron diferentes tipos de agresión (Tabla 1), que van desde la incautación de mascarillas protectoras y su adquisición incluso a precios que triplican su valor normal, hasta la incautación de respiradores y la provisión de test rápidos de la COVID-19 de muy baja eficacia. Entre los países que asumieron un perfil agresivo, ya sea por acciones de incautación de productos sanitarios o por adquisición prepotente ( $\sin$ respeto a las convenciones del comercio internacional), se tienen a Francia, Estados Unidos, Turquía, Tailandia, República Checa y Brasil, además de un país europeo no identificado. Entre los países que sufrieron la agresión se tienen a España, Italia, Bélgica, Alemania, Israel y Paraguay, además de Francia y Brasil.

\section{DISCUSIÓN}

Los sucesos descritos en este estudio, que dieron forma a la llamada guerra de las mascarillas, son tan recientes, que sus impactos todavía no son lo suficientemente claros. Por ello, el intento de entenderlos aparece más imbuido de interrogantes, de inquietudes, e incluso de cuestionamientos, que de explicaciones plausibles. En consecuencia, todo este esfuerzo por ubicar la guerra de las mascarillas en el contexto internacional actual y por asimilarlo en una reflexión sistemática, a modo de marco teórico, es todavía incipiente y parcial, por lo que constituye apenas un primer esbozo, que va más allá de las pretensiones inmediatistas de las publicaciones periodísticas, de un fenómeno tan inesperado, como inusual y revelador.

Lo primero que se puede señalar es que las reglas de juego del comercio internacional, tan cuidadosa y esforzadamente modeladas a lo largo de las últimas décadas, resultaron ineficaces para contener el propósito de diferentes gobiernos por conseguir material de protección sanitaria en los mercados internacionales. ¿Significa esto que la OMC ha trabajado en vano o que debiera hacerse a un lado? Definitivamente, no. En ese sentido, aun cuando en esta oportunidad y ante la situación experimentada podría parecer que el rol de la OMC y el ejercicio de los principios rectores del comercio se vieron severamente golpeados, como bien señalan Foncillas (2020) y Mergier (2020), entre otros, de todos modos es preferible y conveniente contar con un marco regulatorio guía sobre el cual actuar en materia de comercio, antes que no contar con ningún instrumento de regulación y se proceda según el parecer de cada quien.

Segundo, la intervención de Estados Unidos en este conflicto, abiertamente contraria al liberalismo en el que se fundamenta su propia existencia como nación, es coherente con la lógica económica proteccionista de su presidente. No es extraño, entonces, que la administración Trump, y especialmente el presidente Donald Trump, parecieran negarse a reconocer que los datos de la realidad refutan sus prejuicios personales; así como en su momento sostenía prejuicios respecto de los aranceles, las rebajas tributarias, el cambio climático, los acuerdos comerciales, los inmigrantes, hoy los tiene respecto de la pandemia del COVID-19. Estados Unidos se convierte así en el más importante actor de la guerra de las mascarillas, respaldado por el poder económico que lo caracteriza.

¿Significa esto que sigue detentando una primacía hegemónica en el mundo y que los demás estados solo pueden aspirar a ser satélites que lo circundan? Al parecer, no. Los datos examinados muestran que, en casi todos los casos el país proveedor, el país que subyace más allá de los agresores y agredidos, es China. Este dato tiene especial sentido en tanto, como sostienen Meltzer y Shenai (2019), el modelo económico chino tiene un amplio rango de implicaciones, tanto para Estados Unidos como para el resto del mundo. En ese marco, el hecho de que haya sido China no solo la nación en la que se produjo el brote epidémico del COVID-19, con fuertes repercusiones económicas, sino la primera nación que ha conseguido superar la pandemia, la ubica en mejor posición para reiniciar el proceso de recuperación económica.

Hay que destacar, además, que esta recuperación se da sobre la base de una producción claramente centrada en artículos, que hoy por hoy son urgentemente requeridos por muchas naciones (material de protección sanitario, respiradores), los que involucran no solo mano de obra barata, sino también un liderazgo en el uso y generación de tecnología de punta, como apuntan Schneider-Petsinger et al. (2019).

Tercero, la agresión entre países miembros de la Unión Europea, cuestiona no solo los fundamentos doctrinales de orden político en los que esta se sustenta, sino también la eficacia de mediano y largo plazo de los acuerdos en torno al comercio que se habían logrado. La agresión experimentada por España de parte de Francia, y la de Italia a manos de República Checa, muestra que los acuerdos comerciales y los consensos son un débil andamio en el 
cual edificar las relaciones internacionales y el comercio entre naciones. El caso de Brasil y Paraguay (Extra, 2020), ajeno a la Unión Europea, pero también surgido entre estados miembros de un mismo grupo económico (el Mercosur), también da cuenta de esa lectura. ¿Significa esto que la Unión Europea pudiera haber entrado en un periodo de crisis institucional interna? No necesariamente. Pero lo que sí emerge prácticamente como un aprendizaje necesario, es el hecho que, si bien se puede y posiblemente se debe aspirar a ser parte de una comunidad de naciones, es prudente preservar un cierto grado de interés nacional (léase nacionalismo) que serviría como red de seguridad ante acontecimientos inesperados e incontrolables, como los que se experimentaron en la guerra de las mascarillas.

Cuarto, desde un punto de vista teórico, los acontecimientos permiten una lectura a la luz del dilema del prisionero (Leriche y Caloca, 2009), donde cada gobierno actúa con desconfianza frente a los otros, como señala Gozzer (2020), sin considerar que una estrategia de actuación cooperativa sería mucho más beneficiosa para ellos, lo que se inscribiría en la lógica de los acuerdos internacionales sobre el comercio.

\section{CONCLUSIONES}

La guerra de las mascarillas es un conflicto desatado entre varios gobiernos, principalmente estadounidense y europeos, que se generó en el mes de marzo del presente año, con motivo de la escasez de mascarillas y material de protección sanitaria ante la pandemia de COVID-19, que alcanzó a la mayoría de países del mundo y se sigue extendiendo entre ellos. Varios países participaron en el conflicto, entre los cuales destacan Francia, Estados Unidos, España, Alemania, Turquía y otros, algunos como agresores y otros como víctimas en medio de un juego de fuerzas de mercado, que no tuvo en cuenta las reglas del comercio internacional, ni el principio de solidaridad, que se supone, guía las relaciones de cooperación internacional.

\section{REFERENCIAS}

Agosin, M. (2018). Guerra comercial. Revista Economía \& Administración, 173(2018), 6-9.

Arias-Borque, J. (11 de abril de 2020). Guerra por el material médico: del millón de mascarillas españolas que se quedó Francia a los maletines a pie de avión. Libertad Digital. Recuperado de https:/www.libertaddigital.com/internacional/europa/2020-04-03/coronavirus-estado-de-alarmaguerra-mundial-material-sanitario-francia-se-quedo-un-millon-mascarillas-espanolas-1276655287/

Ayuso, S. (02 de abril de 2020). La guerra de las mascarillas enfrenta a Europa y EE UU. El País. Recuperado de https://elpais.com/sociedad/2020-04-02/la-guerra-de-las-mascarillas-enfrenta-a-europa-y-eeuu.html

Barrera G., R. A. (2019). Los Brics y las relaciones internacionales Sur-Sur: el caso de India. Oasis, 30, juliodiciembre, 133-143. doi: https://doi.org/10.18601/16577558.n30.08

Bhattacherjee, A. (2012). Social Science Research: Principles, Methods, and Practices. Textbooks Collection, 3. University of South Florida, Scholar Commons.

Cantón, E. (03 de abril de 2020). El coronavirus desata la guerra de las mascarillas. El Periódico. Recuperado de https://www.elperiodico.com/es/internacional/20200403/guerra-mascarillas-paises-coronavirus7916153

Comisión Económica para América Latina y el Caribe (CEPAL). (2019). Perspectivas del Comercio Internacional de América Latina y el Caribe, 2019 (LC/PUB.2019/20-P). Santiago, Chile: Naciones Unidas.

Cox, S. (ed.) (2008). Economía moderna. Características, hechos y protagonistas. Buenos Aires, España: Cuatro Media.

Damen, M. \& Turunen, T. (2018). Transatlantic relations: USA and Canada. Fact Sheets on the European Union. Recuperado de http://www.iberglobal.com/files/2019-1/rels_trasatlanticos.pdf

Damen, M. (2019). La Unión Europea y sus socios comerciales. Fichas técnicas sobre la Unión Europea. Recuperado de https://www.europarl.europa.eu/ftu/pdf/es/FTU_5.2.1.pdf

Agencia EFE. (14 de abril de 2020). La oposición paraguaya apela al Mercosur para que Brasil libere respiradores. Agencia EFE. Recuperado de https://www.efe.com/efe/america/politica/la-oposicionparaguaya-apela-al-mercosur-para-que-brasil-libere-respiradores/20000035-4221314

Euronews. (03 de abril de 2020). Batalla desleal en la 'guerra' por conseguir mascarillas. Euronews. Recuperado de https://es.euronews.com/2020/04/03/batalla-desleal-en-la-guerra-por-conseguir-mascarillas

Extra. (13 de abril de 2020). Brasil confiscó respiradores que venían para el Paraguay. Extra. Recuperado de 
https://www.extra.com.py/actualidad/brasil-confisco-respiradores-que-venian-el-paraguayn2879773.html

Foncillas, A. (19 de abril de 2020). Como en el salvaje oeste: La guerra global por las mascarillas chinas en medio de la pandemia. El Comercio. Recuperado de https://elcomercio.pe/mundo/actualidad/coronaviruscomo-en-el-salvaje-oeste-la-guerra-global-por-las-mascarillas-chinas-covid-19-noticia/?ref=ecr

Gazol,A. (2016). Libre comercio: tratados y nuevo orden. Un balance. Economía UNAM, 13(38), 122-130.

Giordano, P. (2019). Estimaciones de las tendencias comerciales América Latina y el Caribe. Edición 2019.

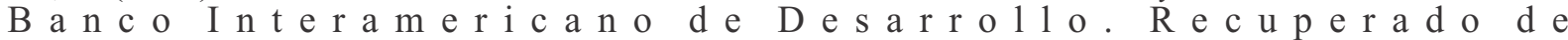
https://publications.iadb.org/publications/spanish/document/Estimaciones-de-las-tendenciascomerciales-america-latina-y-el-caribe-edicion-2019.pdf

Gómez, L. (2011). Un espacio para la investigación documental. Revista Vanguardia Psicológica Clínica Teórica y Práctica, 1(2), 226-233.

Gozzer, S. (11 de abril de 2020). Coronavirus: cómo afecta a América Latina la pugna entre países por conseguir respiradores, ventiladores y mascarillas. BBC News Mundo. Recuperado de https://www.bbc.com/mundo/noticias-america-latina-52233577

Hamilton, D.S. (2019). Transatlantic Policy Impacts of the U.S.-EU Trade Conflict. Subcommittee on Europe, Eurasia, Energy and the Environment, Committee on Foreign Affairs U.S., House of Representatives. Recuperado de https://transatlanticrelations.org/wp-content/uploads/2019/06/HFAC-US-EU-testimonyJune-26-2019-dh-final.pdf

Hidalgo, R. (2020, 03 de abril). Guerra por mascarillas. El Universo. Recuperado de https://www.eluniverso.com/opinion/2020/04/11/nota/7810980/guerra-mascarillas

Idígoras, M.A. (2017). Una decisión que divide a un país y a un continente. La Albolafia: Revista de Humanidades y Cultura, 12(2017), 19-32.

Iglesias, J.P. (06 de abril, 2020). Para Entender: De la guerra contra el virus a la guerra por los ventiladores. $L a$ tercera. Recuperado de https:/www.latercera.com/opinion/noticia/para-entender-de-la-guerra-contrael-virus-a-la-guerra-por-los-ventiladores/YRYJOGCFEFCJJI344ZHW45AFKU/

Jeantet, D. (22 de abril, 2020). Brasil: Gobierno, estados luchan por suministros en pandemia. AP News. Recuperado de https://apnews.com/67a324ec6fc8c8074fc57e6fd7aeb687

Kapustina, L., Lipková, L., Silin, Y. \& Drevalev, A. (2020). US-China Trade War: Causes and Outcomes. SHS Web of Conferences, 73(01012), https://doi.org/10.1051/shsconf/20207301012

Kryazhev, A. (05 de abril de 2020). La guerra de las mascarillas: cómo el mundo lucha por el equipo de protección. Sputnik. Recuperado de https://sptnkne.ws/BWqZ

Leriche, C.E. \& Caloca, O.R. Racionalidad y cooperación: un juego reflexivo Análisis Económico, 24(56), 229250.

Malfeito, J. (2017). Brexit: efectos económicos en un escenario incierto. La Albolafia: Revista de Humanidades y Cultura, 12(2017), 55-74.

Marcus, J. (3 de enero de 2020). Qasem Soleimani: por qué EE.UU. mató al general de Irán ahora (y qué es lo que se espera que ocurra). BBC News Mundo. Recuperado de https://www.bbc.com/mundo/noticiasinternacional-50983463

Meltzer, J.P. \& Shenai, N. (2019). The US-China economic relationship A comprehensive approach. Global Economy and Development at Brookings, February.

Mergier, A.M. (16 de abril, 2020). La guerra de las mascarillas. Proceso. Recuperado de https://www.proceso.com.mx/626047/la-guerra-de-las-mascarillas

Organización Mundial de la Salud. (2020). Nuevo coronavirus - China. Preparación y respuesta ante emergencias. Recuperado de https://www.who.int/csr/don/12-january-2020-novel-coronaviruschina/es/

Organización Mundial del Comercio. (2019). Informe anual 2019. Ginebra, Suiza: Organización Mundial del Comercio.

Pozzi, S. (16 junio de 2019). EE UU encadena el mayor periodo de crecimiento de su historia. El País. Recuperado de https:/elpais.com/economia/2019/06/15/actualidad/1560602434_147668.html

Rosales, O. (agosto, 2018). Las claves del conflicto económico China-Estados Unidos. FLACSO Chile. Recuperado de http://www.flacsochile.org/slider/las-claves-del-conflicto-economico-china-estadosunidos/

Schneider-Petsinger, M., Wang, J., Jie, Y. \& Crabtree, J. (2019). US-China Strategic Competition The Quest for Global Technological Leadership. Asia-Pacific Programme and the US and the Americas Programme. Recuperado de https://www.chathamhouse.org/publication/us-china-strategic-competition-questglobal-technological-leadership\#

Viani, F. (2019). Las recientes tendencias proteccionistas en el ámbito comercial y su impacto sobre la Unión Europea. Boletín Económico, 2(2019), Artículos analíticos. Banco de España.

Recuperado de https://repositorio.bde.es/bitstream/123456789/8452/1/be1902-art11.pdf 